
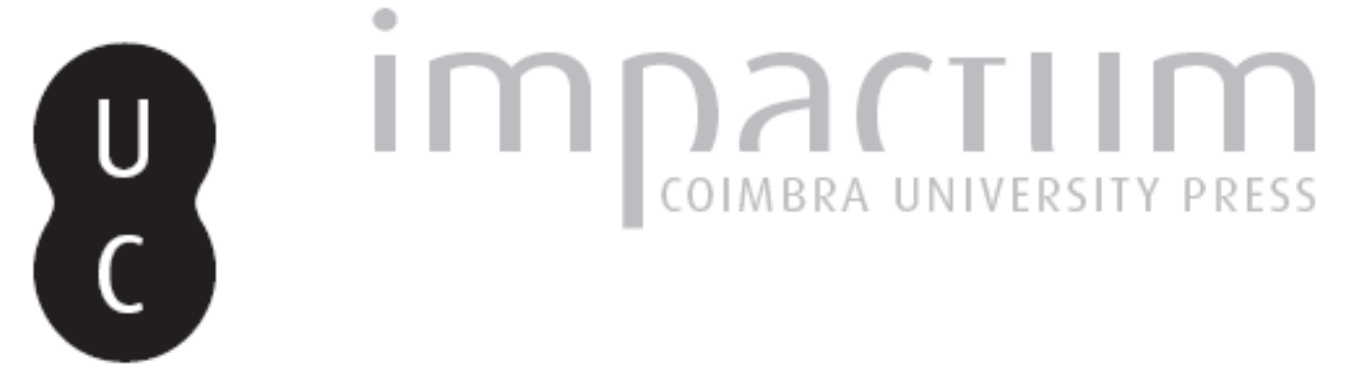

Familiares, víctimas y derechos humanos: la política y tradición jurídica

Autor(es): Heffes, Omar Darío

Publicado por: Universidade Católica de Petrópolis

URL persistente:

URI:http://hdl.handle.net/10316.2/33913

DOI:

DOI:http://dx.doi.org/10.14195/2175-0947_1-1_13

Accessed : $\quad$ 26-Apr-2023 14:31:36

A navegação consulta e descarregamento dos títulos inseridos nas Bibliotecas Digitais UC Digitalis, UC Pombalina e UC Impactum, pressupõem a aceitação plena e sem reservas dos Termos e Condições de Uso destas Bibliotecas Digitais, disponíveis em https://digitalis.uc.pt/pt-pt/termos.

Conforme exposto nos referidos Termos e Condições de Uso, o descarregamento de títulos de acesso restrito requer uma licença válida de autorização devendo o utilizador aceder ao(s) documento(s) a partir de um endereço de IP da instituição detentora da supramencionada licença.

Ao utilizador é apenas permitido o descarregamento para uso pessoal, pelo que o emprego do(s) título(s) descarregado(s) para outro fim, designadamente comercial, carece de autorização do respetivo autor ou editor da obra.

Na medida em que todas as obras da UC Digitalis se encontram protegidas pelo Código do Direito de Autor e Direitos Conexos e demais legislação aplicável, toda a cópia, parcial ou total, deste documento, nos casos em que é legalmente admitida, deverá conter ou fazer-se acompanhar por este aviso. 

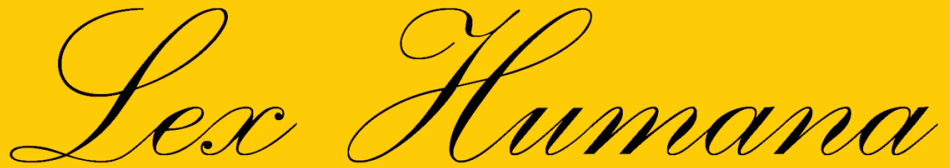

Revista do Programa de Pós-Graduação em Direito da UCP

ISSN(e) 2175-0947

Universidade Católica de Petrópolis Rua Benjamin Constant, 213 - Petrópolis - Centro CEP 25610-130

Tel: (24) 2244-4000 E-mail: lexhumana@ucp.br 


\section{FAMILIARES, VÍCTIMAS Y DERECHOS HUMANOS: LA POLÍTICA Y TRADICIÓN JURÍDICA}

\section{Omar Darío Heffes}

\section{Introducción}

Las fotos de los familiares muertos han invadido las calles. Desde hace aproximadamente treinta años hay un reclamo continuo por la vida y la justicia, un reclamo por estas víctimas. Distintos han sido los perpetradores y distintas han sido las víctimas, sin embargo, hay algo en común que los une a todos.

Ese lazo son los familiares. Los familiares han hecho un esfuerzo magnífico para que sus reclamos pudieran ser escuchados, para conseguir el esclarecimiento de los crímenes, la obtención de una declaración verdadera de lo sucedido y principalmente el juicio y castigo a los culpables.

Se ha formalizado, entonces, un pedido claro hacia uno de los poderes del Estado. Claramente la institución judicial se tuvo que enfrentar en estos últimos treinta años a un requerimiento por parte de los familiares.

Durante estos treinta años el papel del Estado ha variado de manera significativa. El Estado ha propiciado, de manera explícita muchas veces, estas respuestas por parte de los grupos familiares. El Estado, en general, por intermedio de la agencia judicial, no siempre ha respondido de la misma manera. En ciertos casos ha aportado algunas soluciones, tal vez no demasiado claras y en otros no ha podido aportar la solución que han requerido los familiares.

Lo que han buscado los grupos familiares ha siempre tenido en mira al Derecho Penal como marco para lograr su cometido y sin embargo, en general, el Derecho Penal no ha podido aportar soluciones claras a los problemas.

En este trabajo intentaremos ver cual ha sido el papel de la víctima en la sociedad argentina, la vinculación y la posibilidad de una respuesta política por parte de la víctima, y a su vez, si la posición de la víctima y de los familiares no ha sido originada en parte por nuestra tradición jurídica. Como corolario intentaremos ver si la actuación de los familiares y la forma de reacción jurídica no pueden traer aparejada un problema con los derechos 
humanos.

Este trabajo parte del presupuesto de que la política en Occidente ha puesto en juego la vida. Claro ejemplo de esta puesta en juego fue el autodenominado "Proceso de Reorganización Nacional" que con un estado de excepción permanente implicó la muerte organizada y dirigida. A esta puesta en juego, la única respuesta que apareció como posible fue la salida de los familiares a la calle con un discurso que conllevaba discutir en el espacio de la nuda vida, en la cifra misma de la política, imposibilitando una solución que permita una mejora de la condición de víctima y un respeto generalizado de los derechos humanos.

Si bien este movimiento, tiene como momento de inicio a las Madres de Plaza de Mayo, no quiero manifestar con esto que dicho grupo familiar haya propiciado en forma alguna esta imposición discursiva. Lo que si destaco del movimiento de las Madres es la clara preparación para el terreno de esta forma de participación que dio a luz a esta manifestación.

Las Madres tomaron, como lo harían otros grupos, la Plaza de Mayo como lugar fundamental de expresión, este lugar dentro de la historia política argentina tiene una gran trascendencia, entonces la permanencia en ese lugar pareciera implicar un accionar político ${ }^{1}$.

1 "La disputa que mantenían con otros sectores del movimiento de derechos humanos y, particularmente, entre los grupos de familiares y afectados por la represión, ahora se volcaba a su favor porque demostraban que la presencia en la Plaza era eficaz para la denuncia. Eso era, al menos, lo que ellas incansablemente repetían cuando invitaron a otras madres a que las acompañaran aquel jueves. El número aumentó levemente, pero ya habían logrado consolidar un grupo de más de cien familiares dispuesto a pelear con el cuerpo por la Plaza. Y ese día iban a volver a ponerse a prueba.

"La policía empezó a tratar de alejarlas del lugar. Las empujaban y si encontraban resistencia, empezaban a golpearlas. Ellas esquivaban el enfrentamiento, pero no se iban. 'Le peleamos. Nos sacaban y volvíamos a entrar. Nos hacían ir y volvíamos. A veces no lográbamos mucho. Yo viajaba desde La Plata para, a lo mejor, estar un minuto en la Plaza. Pero igual íbamos. Nos habíamos dado cuenta de la importancia de pelear ese lugar' - cuenta Hebe" GORINI, U.; La rebelión de las madres. Historia de las Madres de Plaza de Mayo. Tomo I (1976-1983), Buenos Aires, Norma, 2006, pp. 101-102

"Mucha gente se pregunta por qué habiendo otros organismos las madres fuímos a la Plaza, y por qué nos sentimos tan bien en la Plaza. Y esto es una cosa que la pensamos ahora, no la pensamos ese día; y cuanto más hablo con la gente que sabe más que nosotros, más nos damos cuenta por qué se crearon las Madres. Y nos 
La pregunta por el carácter político de las actividades de los grupos de familiares puede tener una respuesta sencilla. Su contestación depende pura y exclusivamente por como se defina la acción política, pero además, teniendo en cuenta que cualquier respuesta puede estar condicionada por los hechos que hacen que los familiares salgan a la calle entreviéndose, también, como una respuesta política no tradicional.

A pesar de ello, trataremos de esbozar una definición, pero que, desde ya, no implica desaprovechar conceptos o alternativas a la misma, incluso puede ser mejorada más allá del esbozo que presento aquí. Intentaré entonces esa definición a partir de algunos textos de Arendt para establecer un concepto posible de política.

Para esta autora la acción y el discurso, siguiendo en su razonamiento a Aristóteles, es lo que define la política ${ }^{2}$, y para ello se debe tener presente que

[...] la pluralidad humana, básica condición tanto de la acción como del discurso, tiene el doble carácter de igualdad y distinción. Si los hombres no fueran iguales, no podrían entenderse ni planear y prever para el futuro las necesidades de los que llegarán después. Si los hombres no fueran distintos, es decir, cada ser humano diferenciado de cualquier otro que exista, haya existido o

creamos porque en otros organismos no nos sentíamos bien cerca; había siempre un escritorio de por medio, había siempre una cosa más burocrática. Y en la Plaza éramos todas iguales. Ese “¿qué te pasó?”, “¿cómo fue?”. Éramos una igual a la otra; a todas nos había llevado hijos, a todas nos pasaba lo mismo, habíamos ido a los mismos lugares. Y era como que no habría ningún tipo de distanciamiento. Por eso es que la Plaza agrupó. Por eso es que la Plaza consolidó" De la conferencia pronunciada el 6 de julio de 1988 en Liber/Arte por la presidenta de la Asociación Madres de Plaza de Mayo publicado en AA.VV.; Historia de las Madres de Plaza de Mayo, Buenos Aires, Editorial La Página, 1995, p. 11.

2 "La acción... sólo es política si va acompañada de la palabra, del discurso. Y ello porque, en la medida en que siempre percibimos el mundo desde la distinta posición que ocupamos en él, sólo podemos experimentarlo como mundo en común en el habla. Sólo hablando es posible comprender, desde todas las posiciones cómo es realmente el mundo. El mundo es pues lo que está entre nosotros, lo que nos separa y nos une" BIRULÉS, F.; Introducción en ARENDT, H.; ¿Qué es la política?, Barcelona, Paidos, 1997, pp. 18-19 
existirá, no necesitarían del discurso ni la acción para entenderse ${ }^{3}$.

En forma resumida una vía interpretativa del concepto de política habla necesariamente de una acción y un discurso que se tiene en un ambiente de pluralidad ${ }^{4}$.

En esa instancia la existencia constante de diferentes grupos familiares ha conllevado la perpretación de la nuda vida en el discurso político, no ya como un efecto deseado o buscado, sino simplemente por ser en parte la forma de discutir o el terreno disponible para hacerlo, siendo entonces un arma de doble filo político que implica un doble mecanismo de control: a) una homogeneidad discursiva y b) una disposición a la participación directa y constante del Estado a nivel represivo. Pero a su vez, se puede ver, en forma genealógica, que esta homogeneidad discursiva depende también de la forma en que las agencias judiciales pueden responder a este problema. La imposibilidad de una verdad construida dentro del ámbito judicial coloca a las víctimas fuera de ese lugar propiciando una confusión entre política y ética inescindible, impidiendo conseguir su participación y finalmente alguna solución definitiva para sus casos.

Por intermedio de este trabajo trataremos tres cosas a partir de la salida de los grupos familiares: a) cual es la respuesta posible por parte de la agencia judicial b) si los grupos familiares desarrollan algún tipo de política, y c) tomando el lugar apolítico y el afuera de la agencia judicial como una nueva construcción de una forma de "verdad" que homogeneiza el discurso y que conlleva un discurso limitado de los derechos humanos.

\section{El lugar de la tradición jurídica}

Toda la segunda mitad de la Edad Media asistirá

3

ARENDT, H.; La condición humana, Buenos Aires, Paidos, 2003, p. 200. 4 "Todas las actividades humanas están condicionadas por el hecho de la pluralidad humana, por el hecho de que no es un hombre, sino los hombres en plural quienes habitan la tierra y de un modo u otro viven juntos. Pero sólo la acción y el discurso están conectados específicamente con el hecho de que vivir siempre significa vivir entre los hombres, vivir entre los que son mis iguales" ARENDT, H.; Labor, trabajo y acción. Una conferencia en ARENDT, H.; De la historia a la acción, Buenos Aires, Paidos, 2005, p.103. Este resumen va más allá de las características de la acción que veremos más adelante. 
a la transformación de estas viejas prácticas y a la invención de nuevas formas de justicia, de prácticas y procedimientos judiciales. Formas que son absolutamente capitales para la historia de Europa y el mundo entero, en la medida en que Europa impone violentamente su yugo a toda la superficie de la tierra. (...) En el derecho de esa época se inventó una determinada manera de saber, una condición de posibilidad de saber. En el derecho de esa época se inventó una determinada manera de saber, una condición de posibilidad de saber cuya proyección y destino será capital para Occidente. Esta modalidad de saber es la indagación $[\ldots]$. $^{5}$

Estas nuevas formas de justicia que se desarrollan en parte de occidente tienen que ver con el derecho romano y la mezcla con el derecho germánico dando lo que hoy conocemos como tradición continental o tradición civil. En ésta tiene validez una forma particular de ejercer tanto el poder como la justicia. Esta forma que es contraria a la otra tradición occidental del common law podría resumirse de la siguiente manera: "The criminal procedure in the civil law tradition is 'inquisitorial', while that in the common law tradition is "accusatorial"'

Esta división entre sistema inquisitorial o acusatorio tiene como clara diferencia la participación posible que se da en la justicia por parte de los individuos. Es una clara diferencia de procedimiento que origina una diferencia fundamental en esa participación. En el caso de la forma acusatoria las partes resuelven el daño que una le ha infringido a otra ${ }^{7}$, en

5 FOUCAULT, M.; La verdad y las formas jurídicas, Barcelona, Gedisa, 2005 , p. 75.

6 MERRYMAN, J. H.; The civil law tradition. An introduction to the legal systems of Western Europe and Latin America, Stanford, Stanford University Press, 1969, p. 134.

7 This same right of accusation is soon extended to his relatives, and as conception of social solidarity and the need for group protection develops, the right of accusation extends to all members of the group. A presiding officer is selected to hear evidence, decide, and sentence; he does not, however, have the power to institute the action or to determinate the questions to be raised or the evidence to 
cambio en la forma inquisitorial hay un intermediario que toma para sí la ofensa, se hace cargo de ella y busca una compensación por el daño. Esa otra parte es el Estado:

A partir del momento en que el soberano o su representante, el procurador, dicen: 'Yo también he sido lesionado por el daño', resulta que el daño no es solamente una ofensa de un individuo a otro, sino también una ofensa que infringe un individuo al Estado, al soberano como representante del Estado, un ataque no al individuo sino a la ley misma del Estado. [...] La infracción no es un daño cometido por un individuo contra otro, es una ofensa o lesión de un individuo al orden, al Estado, a la ley, a la sociedad, a la soberanía, al soberano. La infracción es una de las grandes invenciones del pensamiento medieval. Se ve así como el poder estatal va confiscando todo el procedimiento judicial, el mecanismo judicial, el mecanismo de liquidación de los litigios entre individuos de la alta Edad Media. ${ }^{8}$

En este mecanismo de liquidación de los litigios entre individuos se podrá ver una explicación posible del drama familiar y la imposibilidad de encontrar una respuesta dentro de la agencia judicial ${ }^{9}$. Esto es así ya que la construcción de la verdad dentro del espacio inquisitorial no está dada por

be introduced, and he has no inherent investigative powers. These matters are in the hands of the accuser and the accused. The criminal trial is a contest between the accuser and the accused, which the judge as a referee. Typically the proceeding takes place publicity and orally, and is not preceded by any official investigation or preparation of evidence" MERRYMAN, J. H.; op. cit., p. 135.

8 FOUCAULT, M.; op. cit., pp. 79-80.

9 "Una justicia que no es más pleito entre individuos y libre aceptación de estos individuos de ciertas reglas de liquidación sino que, por el contrario, se impondrá a individuos, oponentes, partidos. Los individuos no tendrían en adelante el derecho de resolver, regular o irregularmente sus litigios deberán someterse a un poder exterior a ellos que se les impone como poder judicial y político" FOUCAULT, M.; op. cit., pp. pp. 78-79. 
la participación de las partes, sino y muy por el contrario por la decisión de un tercero imparcial que determina quien ha probado tener la razón ${ }^{10}$. En nuestro sistema judicial el juez, tal y como es la tradición de civil law, "podrá ordenar la reconstrucción del hecho para comprobar si se efectuó o pudo efectuarse de un modo determinado". ${ }^{11}$ Concordante con esto también es el artículo 239 del Código Procesal Penal de la Nación Argentina establece que "el juez interrogará a toda persona que conozca los hechos investigados, cuando su declaración pueda ser útil para descubrir la verdad"12

Por el lado contrario, las víctimas no les basta con esta construcción judicial, que entre otras cosas impone límites a la investigación, límites que tienen origen con defensa de derechos relacionados con el acusado, cuestión que debe ser puesta en evidencia y que de se debe prestar crucial atención pero que impide lograr el objetivo deseado por los familiares. Se debe tener 10 A exposição de motivos introduz o texto do Código de Processo Penal explicita ser objetivo do processo judicial criminal a descoberta da "verdade real", ou material, (...). Por isso, o juizes podem e devem tomar a iniciativa de trazer aos autos tudo o que pensarem interessar ao processo, ex officio, para formar o seu "livre convencimento" examinando a "prova dos autos". (...) Como se vê, a ênfase está depositada no interesse público - aqui compreendido como aquele definido pelos funcionários do Estado - servindo o processo para incrementálo, acima dos interesses individuais, ou mesmo coletivos. KANT DE LIMA, R., "Direitos civis e direitos humanos. Uma tradição judiciária pré-republicana?" en São Paulo em Perspectiva, 18 (1), 2004, p. 52. Si bien el autor se refiere a la justicia brasileña, nuestra tradición jurídica es la misma y exige en el derecho penal la formación de la verdad material.

"En el proceso penal se necesita certidumbre con grado de apodíctica - que la conclusión es así y no puede ser de otro modo - para sustentar una sentencia de condena" D’ALBORA, F. J.; Código Procesal Penal de la Nación. Anotado, comentado, concordado, Buenos Aires, Abeledo Perrot, 2003, Tomo I, p. 453. 11 Ese es el texto del artículo 221 del Código Procesal Penal de la Nación Argentina, si bien dicho texto tiene origen recién en el año 1994, es notorio que dicho código ha tenido intención de incorporar una faz acusatoria al proceso penal argentino, sin embargo se mantiene la principal función judicial que es la construcción de lo que ha sucedido verdaderamente.

12 También se debe recordar el artículo 240 que establece que "toda persona tendrá la obligación de concurrir al llamamiento judicial y declarar la verdad de cuanto supiere y le fuere preguntado, salvo las excepciones establecidas por la ley". Estas excepciones están relacionadas con por ejemplos secretos profesionales que impiden develar la verdad del asunto, pero es claro que el llamamiento a decir la verdad funciona como necesario para la consecución del proceso. 
en cuenta que todos los casos de familiares en la calle no han sido iguales, en algunos casos claramente el Estado argentino pretendió imponer una sombra y un manto de olvido en la investigación judicial propiciando, justamente, la imposibilidad para los peticionarios, imposibilidad generada también por cuestiones procesales que tienen su origen también en nuestra tradición jurídica. ${ }^{13}$

Los familiares precisan, desde su reclamo ético, una verdad, una historia que concuerde con haber roto su familia, la verdad debe permitirles ser familia, desarrollar lo que se ha roto. La pregunta por la muerte del familiar no importa tanto como fue realizada, sino el como pudo ser posible, y en algunos casos sólo importa la existencia del cuerpo para poder dar un entierro definitivo al ser querido, y, definitivamente, lograr el status familiar póstumo. De esta manera, las víctimas desde su reclamo están solicitando un lugar claro que le permita rearmar su verdad, una verdad que finalmente les permita volver a sus casas.

Pero justamente, una cuestión que no se puede resolver por la tradición jurídica es algo que en el modelo acusatorio está resuelto de otra forma, en ese tipo de juicios la verdad se construye y las partes tiene una actuación directa que les permite construirla, en cambio en la tradición civil esto no ocurre ya que lo inquisitorial busca la "verdad real", tal y como vimos, una imposibilidad en la cual se termina condenando a los familiares a un único camino, a una única posibilidad que no puede ser llevada a cabo por el poder judicial y tampoco fuera de él. El familiar pretende construir algo imposible dentro de la agencia judicial, pretende finalmente que una declaración pueda liberarlo de la falta.

De esta manera tenemos a los familiares solicitando claramente por alguna verdad que los permita construirse como familia, intentando reclamar políticamente sin lograrlo, discutiendo por la nuda vida y teniendo un reclamo ético cuyo lugar de realización está cerrado porque esa verdad no puede ser construida y lo que puede ser construido nunca puede ser suficiente, siempre requiere de algo más que les permita participar, que les permita poder ser los protagonistas de esa construcción, de esa realización. Sin embargo, eso parece ser imposible. Entonces hay un nuevo armado que tiene que ver con

13 Recordemos los casos de violaciones perpetradas contra los derechos humanos que con leyes tales como la "Obediencia debida" y ley de "Punto final" establecían cortapisas para la investigación. En un caso era por cuestiones de relaciones jerárquicas dentro del ejercito y en el segundo caso se trataban de cuestiones relacionadas con plazo para la prescripción. 
la posición del último e irreductible lugar de los derechos. Los familiares parecen decir, y exacerban su discurso en ello, que los derechos conculcados son los de ellos, los únicos posibles de ser conculcados, y, por ende, los únicos posibles de ser revindicados. Esos deben ser los únicos por encima de todos los demás ${ }^{14}$.

\section{Los lugares de la familia}

En el año 1977 los familiares de desaparecidos firmaron una solicitada que afirmaba:

A la Junta Militar del Gobierno de las Fuerzas Armadas. Los Familiares de Desaparecidos y Detenidos vemos nuestros hogares destrozados por la angustia y la incertidumbre al no saber dónde o cómo están nuestros seres queridos, hasta cuándo sufrirán detención sin causa o cuál será la pena para los acusados.

Somos partidarios del dialogo, estamos empeñados en lograr un país avanzado, próspero y feliz. Para que todas las familias puedan contribuir a realizar este objetivo necesitamos PAZ y la PAZ no es posible sin el amparo de la JUSTICIA.

14 "Cuerpos asesinados en el marco de un mismo delito: el secuestro. Secuestros separados por 25 años. Secuestros separados por un abismo: matar desde el terrorismo de Estado y matar por robar. El resabio violento de secuestrar y matar que 21 años de democracia no pudieron borrar. El secuestro seguido de muerte, desde el Estado hasta los márgenes de la sociedad. Siempre bajo un mismo paraguas: la impunidad". GUAGNINI, L.; Blumberg en el nombre del hijo, Buenos Aires, Sudamericana, 2005, p. 111. Así se establece una extraña línea entre terrorismo de Estado y delincuencia común. Esta línea peligrosa termina aunando incluso grupos de diferente orientación política e ideológico, volviendo terrible las consecuencias de los pedidos definitivos. Pareciera, entonces, que lo político no importa, lo importante es que el lugar es indiscutible, la pérdida del hijo hace imposible que el lugar sea indiscutible y dando una vuelta de tuerca más a la relación entre terrorismo de Estado y delincuencia común nos damos cuenta que la sociedad construida, sólo es una sociedad de víctimas que sufren la disolvente actuación de los perpetradores, mejor aún la delincuencia común termina siendo tan terrible como el terrorismo de Estado. 
Por ello, PETICIONAMOS: - La búsqueda de los ciudadanos desparecidos. - La aparición de los ciudadanos detenidos. - La liberación de los detenidos sin causa y/o proceso y/o la opción Constitucional para salir del país. - El juzgamiento de acuerdo con la Constitución Nacional y las leyes de los que tuvieron causa y/o proceso. ${ }^{15}$

Ante lo terrible, ante la terrible constatación, los familiares de desaparecidos hicieron y utilizaron todos los medios que tenían a su alcance a fin de saber algo sobre sus seres queridos ${ }^{16}$.

El camino que deben seguir los familiares es tortuoso, caminos que los alejan de sus lugares de familia, esos lugares que se van esparciendo y cambiando de forma. Encontrándose con una nueva forma de familia pública, una nueva familia que está instalada en la arena política y que por consiguiente reconstruye su lugar desde la ausencia y desde el lugar público. "Quedamos solos, nosotros solos. Desde ese momento, mis amigos y mi familia fueron las Madres de Plaza de Mayo"17

En apariencias el lugar de la familia ha sido siempre delimitado al lugar del hogar, al lugar de la casa. Así es que Giorgio Agamben, siguiendo a distintos autores, hace un raconto sobre la diferencia entre el oikos y la pólis, lugares en el que se desarrollan distintos tipos de actividades y que tienen distintas finalidades, en el oikos, lugar de la familia, se pretende conservar la vida como el simple hecho de vivir y en el segundo se pretende una vida

15 Solicitada publicada el día 3 y el 28 de septiembre de 1977 en el Diario La Prensa, firmada por aproximadamente 400 firmas citado por GORINI, U.; $o p$. cit., pp. 120-121.

16 "Madres, así no conseguimos nada. Nos mienten en todas partes, nos cierran todas las puertas. Tenemos que salir de este laberinto infernal que nos lleva a recorrer inútilmente despachos oficiales, cuarteles, iglesias y juzgados. Tenemos que ir directo a la Plaza de Mayo y quedarnos allí hasta que nos den una respuesta. Tenemos que llegar a ser cien, doscientas, mil madres hasta que nos vean, hasta que todos se enteren y el propio Videla se vea obligado a recibirnos y darnos una respuesta”. Extracto de la arenga de Azucena Villaflor de Vincenti, citado por GORINI, U.; op. cit., p. 63.

17 Bonafini, Hebe; "Pariendo espacios nuevos. Primera clase de la materia Historia de las Madres de Plaza de Mayo", en América Libre, 17 de octubre de 2000, p. 150, citado por GORINI, U.; op. cit., p. 83. 
calificada $^{18}$.

La presencia inicial de la Madres de Plaza de Mayo tenía la intención primera de exigir - antes que acusar - a quien se erigía como autoridad máxima de la Nación que respondiera por la suerte de los desaparecidos. Era un camino para salir del laberinto infernal de intrincados pasillos oficiales, judiciales, antesalas de políticos y religiosos que terminaban frustrando la denuncia de los crímenes, y para interpelar directamente al poder político ${ }^{19}$

En concreto, el primer objetivo de las Madres, y se reiterará en los otros movimientos familiares, es la concreta denuncia de los hechos que motivaron su salida a la calle.

[...] La desaparición es un vacío, un agujero, una tormenta, un ciclón que destruye, que se lleva todo, que arrastra todo y que una tiene que tratar de contener, de conservar y de sostener. No es fácil cuando el hijo no está más ni en la casa, ni en el trabajo, ni en la mesa, ni en la cama. [...] Desde esta ingenuidad de la pregunta, de esta ingenuidad política, inocencia o ignorancia salimos las Madres a buscar a los hijos ${ }^{20}$.

Esa salida primigenia y fundamental esta relacionada directamente con el mantenimiento de la familia y de la vida de sus miembros.

Este mantenimiento, y todos los mecanismos para aferrarse a ella, son parte de la labor en términos de Arendt. "Por medio de la labor, los hombres producen lo vitalmente necesario que debe alimentar el proceso de la vida del cuerpo humano. Y dado que este proceso vital, a pesar de conducirnos en un progreso rectilíneo de declive desde el nacimiento a la muerte es en si mismo circular, la propia actividad de la labor debe seguir el

18 AGAMBEN, G.; Homo sacer. El poder soberano y la nuda vida, Valencia, Pre-textos, 1998, pp. 9-10. Por ese motivo Aristóteles habla de un "vivir bien", este tiene el agregado de "bien" ya que se está hablando de una vida calificada.

19 GORINI, U.; op. cit., p. 65.

20 Bonafini, Hebe; "Pariendo espacios nuevos. Primera clase de la materia Historia de las Madres de Plaza de Mayo", en América Libre, 17 de octubre de 2000, p. 150, citado por GORINI, U.; op. cit., p. 82. 
ciclo de la vida" ${ }^{21}$.

Por eso es que justamente los reclamos que tienen como eje a la vida se deben explícitamente a una búsqueda de su mantenimiento, sin aditamentos, como el simple hecho de vivir.

El pedido por la vida simple tiene directa relación con la categoría animal laborans que utiliza Arendt. "El animal laborans es sólo uno, a lo sumo el más elevado, de la especie animal que puebla la tierra". Este lugar esta dado justamente por la dependencia con la necesidad, dada esta última por "lo que los hombres compartían con la otras formas de vida animal"22

La productividad del poder de la labor sólo produce objetos de manera incidental y fundamentalmente se interesa por los medios de su propia reproducción puesto que su poder no se agota una vez asegurada su propia reproducción, puede usarse para reproducción de más de un proceso de vida, si bien no 'produce' más que vida ${ }^{23}$.

Vida como el simple y acotado hecho de vivir, vida relacionada con el proceso vital que va desde el nacimiento hasta la muerte y que es garantizada por la labor y dentro del oikos, como el lugar en donde la familia se encuentra.

Tiene 22 años y marcha sin cesar desde hace 78 semanas, cuando mataron a su tío durante un robo: marchó en los tribunales, en la comisaría, en el Ministerio de Justicia y en la cuadra de Adrogué donde fue el crimen. 'Al principio éramos 100, luego 20, después 8 , hasta que en las noches de invierno quedamos cinco. Y las cinco estamos acá. Me encanta que venga toda esta gente. Pero

21 ARENDT, H.; Labor, trabajo y acción. Una conferencia en De la historia a la acción, Buenos Aires, Paidos, 2005, p. 93. Así Aristóteles sitúa esta tarea en la casa relacionándola con la procreación (Política, 1253 b). A eso mismo se refiere Aristóteles, cuando cita a Carondas y a Epiménides de Creta, haciendo una expresa referencia a la comida como cosa compartida en el seno familiar.

ARENDT, H.; La condición humana, Buenos Aires, Paidos, 2003, p. 100 
se tiene que mantener', pide. Y agrega: 'En Argentina, la inseguridad mató más gente que la guerra de Irak. Muchos de los que vinimos somos gente sin papá, sin hermano, sin tío'. Los que no llegaron a la marcha por sus muertos, llegaron por los muertos del vecino, o por el miedo. El miedo de ser el próximo ${ }^{24}$.

Al pasar la calle el contacto con la gente fue intenso. Hobert recordaría: 'Ahí nos dimos cuenta que estábamos en la Plaza de la Víctimas del Silencio. Todos habían perdido a alguien. A cada paso que dabas la gente te quería agarrar diciendo: 'Me mataron un hijo, a mi papá, violaron a tal...'. En el camino nos afanaron a todos, tardamos como media hora hasta llegar'. ${ }^{25}$

Los familiares han salido a reclamar entre otras cosas su derecho a ser familia, su derecho a formar parte de una familia que por diversas razones ha sido rota, ha sido descompuesta. Este reclamo conlleva también el mantenimiento de la familia como un grupo en donde la vida se manifiesta en su más estricto sentido, en el "simple hecho de vivir" 26 , en el grupo que impone a partir de sus normas de mantenimiento de la vida la forma en que esta vida se conserva, un grupo que tiene sus costados politizados y que está a su vez imposibilitado de salir de este umbral en dónde se pone en juego lo

24 "Vinimos muchos sin papá, sin hermano, sin tío" en Clarín, 2 de abril de 2004 (consultado de la edición digital en http://www.clarin.com diario/2004/04/02/g-735370.htm). Esta forma de concebir el miedo de ser el próximo es absolutamente hobbesiano en donde lo que se encuentra en total peligro es la propia vida y por eso tiene sentido el Leviatán. Hobbes expresamente hace una introducción de la vida en la política, politiza el simple hecho de vivir. "La gran metáfora del Leviatán, cuyo cuerpo está formado por todos los cuerpos de los individuos, ha de ser leída a esa luz. Son los cuerpos, absolutamente expuestos a recibir la muerte, de los súbditos los que forman el cuerpo político de Occidente" Agamben, Giorgio; op. cit., p. 159. Las negrillas son del original 25 GUAGNINI, L.; Blumberg. En el nombre del hijo..., p. 165.

26 AGAMBEN, G.; op. cit., p. 9. 
privado y lo público ${ }^{27}$.

En ese punto la denuncia, con esa pretensión, pierde valor de la acción política, ya que busca la simple restitución de una situación o la compensación de la misma, y esta es la tarea posible del Poder Judicial (lugar por excelencia de la denuncia), pero además porque justamente con la relación que termina teniendo la denuncia con la esfera de la labor lo único que se puede desarrollar es la simple reproducción de la vida pero justamente desde un ámbito indefinido, imposible de determinar ya que los familiares intentan perpetrar la familia en la arena pública, o sea publicitan actos privados, actos domésticos que no pueden ni siquiera tener la trascendencia de la propia acción y del discurso.

"La familias se fundan como albergue y fortificación en un mundo inhóspito y extraño en el que uno desea establecer parentescos. Este deseo conduce a la perversión fundamental de lo político[... $]^{228}$

La idea del pedido de justicia está basado en un restablecimiento a condiciones anteriores, de ser posible, y sino a una directa compensación ya sea aplicando una pena o estableciendo un valor monetario al daño inflingido. ${ }^{29}$ Desde ese punto de vista la práctica de la denuncia, o el pedido de justicia jamás pueden ser una acción de la pluralidad sino el simple mantenimiento del ciclo vital.

Creo que uno de los requisitos para que esa justicia exista en un país tan golpeado es que, como insistentemente reclaman las Abuelas de Plaza de Mayo, los nietos secuestrados e ilegalmente adoptados bajo el amparo de la dictadura militar sean restituidas a las legítimas familias. [...] Largas e intensas conversaciones con médicos, psicólogos, jueces y con los parientes de los niños desaparecidos me convencieron de que, casi sin excepciones, la restitución de esas criaturas no sólo tiene su fundamentación ética en el reclamo

27 Para esto, para la delimitación de este umbral en dónde hecho y derecho se ponen en juego ver lo sostenido por Agamben en la Parte Primera de Homo sacer en dónde habla de la "Paradoja de la Soberanía". (Op. Cit., pp. 27-44)

28 ARENDT, H.; ¿Qué es la política?..., p. 46.

29 La idea de este opúsculo no es establecer una discusión sobre el fin de la pena sólo tomo los rasgos generales de una posible intervención judicial. 
de justicia es también el más sano de los destinos que la sociedad puede ofrecerles. ${ }^{30}$

\section{La imposibilidad del disenso}

La familia, para los antiguos, era un conjunto de relaciones desiguales que estaban naturalizadas. Esto era así porque el lugar de la casa, del oikos, es el lugar de la necesidad. Esta necesidad está íntimamente relacionada con el consumo, con ese consumo que no deja nada tras de sí $^{31}$.

El problema que justamente conlleva una relación familiar entonces al ser publicitada, al exponerse al campo público es que deriva de por sí sus condiciones, sus "títulos". Una madre en el ámbito público no varía, sino que publicita justamente algo que es privado, que debe permanecer oculto y que al tener trascendencia pública impone las propias reglas de su status ${ }^{32}$.

El ejemplo de las Madres de Plaza de Mayo es paradigmático. Las Madres son iguales entre sí, pero no iguales con el contexto que las rodea. Se sienten iguales ellas mismas y por eso pueden unirse y reconfortarse. ${ }^{33}$

30 Theo Van Boven, ex director de la División de Derechos Humanos de las Naciones Unidas en HERRERA, M. - TENENBAUM, E.; Identidad despojo y restitución, Buenos Aires, Abuelas de Plaza de Mayo, 2001, p. 11.

31 "En la Plaza, las Madres se contaban sus historias que, en realidad, eran fragmentos de un mismo dolor. Por fin encontraban un lugar donde podían hablar y no sentirse rechazadas, como les ocurría en la mayoría de los sitios donde iban, e incluso muchas veces, en sus propios hogares" GORINI, U., op. cit., p. 83. "A veces me mostraban planchas con siete cuerpos, uno para un lado, de cabeza, y otros para el otro lado, de los pies; estaban todos baleados, algunos con las manos cortadas, me decían que era para identificarlos. Era horrible. Y sin embargo, yo no les tenía asco ni impresión, los hubiera abrazado a todos" (Testimonio de Beatriz Ascardi de Neuhaus citado por GORINI, U., op. cit., p. 78.

32 "Y en la Plaza éramos todas iguales. Ese ‘qué te pasó?', ‘¿cómo fue?'. Éramos una igual a la otra; a todas nos había llevado hijos, a todas nos pasaba lo mismo, habíamos ido a los mismos lugares. Y era como que no habría ningún tipo de distanciamiento. Por eso es que la Plaza agrupó. Por eso es que la Plaza consolidó" De la conferencia pronunciada el 6 de julio de 1988 en Liber/Arte por la presidenta de la Asociación Madres de Plaza de Mayo publicado en AA.VV.; Historia de las Madres ..., p. 11.

33 "En esta forma de organización [organizaciones políticas a partir de la familia], efectivamente, tanto se disuelve la variedad originaria, como se destruye la igualdad esencial de todos los hombres. En ambos casos, la ruina de la política 
Por eso hay una imposibilidad de establecer una organización política que esté basada en la familia o que tenga a la familia como centro. Las relaciones desiguales impiden el ejercicio de una acción y un discurso en un ámbito de pluralidad de iguales y diferentes. ${ }^{34}$

Lo que existe es la creación de un discurso que delimita los lugares posibles. Este discurso dispone a la vida, a la nuda vida, como su objeto fundamental y lo relaciona justamente con su puesta en protagonismo que debe ser defendida explícitamente. Sino es así, en apariencias, se abandona a la nuda vida, el discurso de los familiares se explicita para no abandonar a la vida desnuda, pero aún más se la pone en evidencia. Este discurso tiene como centro a la víctima que aún más queda victimizada en este lugar. Este mecanismo entrampa también a los familiares colocándolos en casi una disyuntiva imposible ${ }^{35}$.

Pero a su vez, en este discurso, dentro del proceso de salida de la familia, está ligado con una especie de liturgia de la víctima y que efectivamente tiene que ver con la vulnerabilidad de los familiares ${ }^{36}$, tiene su centro y su solución en perpetrar esta vulnerabilidad y como solución posible es perpetrar esa vulnerabilidad ${ }^{37}$.

resulta del desarrollo de cuerpos políticos a partir de la familia"ARENDT, H.; ¿Qué es la política?, p. 46.

34 Un ejemplo claro puede ser el Petitorio "Blumberg" (esto es más allá de las ideas que puede tener su propiciador). Este petitorio planteaba un montón de medidas que en apariencias facilitaban una mayor protección a las posibles víctimas de los delitos, pero planteaban medidas que crean una vigilancia tan extrema que terminan consiguiendo una vida pormenorizada, puesta en peligro, controlada y controlable.

(Petitorio publicado en Clarín, 2 de abril de 2004)

35 "Esa sensación de historia repetida en el dolor materno de más de tres décadas fue sintetizado por la actriz Gabriela Toscano: 'El nuestro parece un país que tiende a que nuestros hijos desaparezcan; me de escalofríos pensarlo, pero la injusticia se repite de diferentes maneras'." "En su Día, las madres piden justicia" en Clarín, 15 de octubre de 2005 (extraído de la edición de internet de ese matutino en http://www.clarin.com/diario/2005/10/15/sociedad/s-06201.htm - negrilla en el original).

36 Quizás se podría analizar lemas tales como "Aparición con vida”, no discuto bajo ningún punto de vista su importancia, pero se puede entender que perpetua la vulnerabilidad de esa vida desnuda, nunca la deja en paz, nunca la termina dejando y siempre renueva su estigma.

37 Foucault desarrolla en El orden del discurso los sistemas de exclusión 
Justamente por eso el lugar que cumple la tradición jurídica en promotor de un espacio afuera del Poder Judicial es fundamental, se condena a los familiares a ser familia afuera de su ámbito privado y también afuera del ámbito judicial. El Poder Judicial pareciera decir que la verdad construible ya se encuentra construida imposibilitando a los peticionarios terminar de construir su historia. Esto es claro ya que la imposibilidad de enfrentarse con los acusados a fin de obtener alguna razón, algún retazo de pista por parte de ellos fue propiciado por la agencia judicial. Por consiguiente, este lugar familiar nos representa a todos, termina siendo el último bastión de la dignidad construyendo otra nueva verdad, y esta vez absolutamente incontrovertible.

La verdad del familiar es la verdad más íntima la verdad del sufrimiento, ante eso la "liturgia de la víctima" finaliza una construcción fina y definitiva, este sufrimiento es la razón por la cual el familiar debe ser respetado y es también indiscutible política y éticamente.

Esta liturgia crea a partir del lugar de la denuncia un lugar único que está ligado a la legitimidad del hablar. Sólo puede hablar el que ha sido víctima, sólo puede hacerlo el que ha sabido el dolor sufrido, y sino es así, sólo está autorizada la persona que comulga con este dolor y se alía con la víctima y sostiene sus consignas. ${ }^{38}$

Esto quiere decir que cuando no hay relación de igualdad, puede haber una imposición directa del discurso que se debe producir, imposibilitando así la realización básica de la política que es acción más discurso. Si el discurso es uno solo, por consiguiente, no se permite la pluralidad. Por consiguiente, se fuerza a la sociedad, en forma capilar, a que comparta las consignas de los grupos familiares ${ }^{39}$

de los discursos. "En una sociedad como la nuestra son bien conocidos los procedimientos de exclusión. El más evidente, y el más familiar también, es lo prohibido. Se sabe que no se tiene derecho a decirlo todo, que no se puede hablar de todo en cualquier circunstancia, que cualquiera en fin, no puede hablar de cualquier cosa. Tabú del objeto, ritual de la circunstancia, derecho exclusivo o privilegiado del sujeto que habla..." (FOUCAULT, M.; El orden del discurso, Barcelona, Tusquets, 1992, 4 edición, pp. 11 y 12).

38 De esta manera consignas tales como "Por la vida de nuestros hijos" o "para que no se repita" funcionan como una cortapisa mínima en la cual no se puede estar en desacuerdo.

39 El caso de los teléfonos celulares (Vease, Petitorio publicado en Clarín, 2 de abril de 2004). Así por ejemplo las declaraciones aparecidas en el mismo medio "Para Blumberg, 'de qué sirve que tengamos nuevas leyes y por otro lado están los 
No estoy diciendo con esto que la Madres hayan pretendido imponer un discurso único, pero si que el lugar de la víctima se recrea y está exacerbado en los nuevos movimientos, lugares de palabras absolutas y prescripciones de carácter total. Como ejemplos se puede recordar el llamado Petitorio "Blumberg", que más allá de sus dislates jurídicos solicitaba prescripciones legales de dudosa amplitud y que podían ir claramente en contra de la privacidad. ${ }^{40}$

También es clara esta imposición en el caso de Cromañon. Cuando el ex Jefe de Gobierno fue sobreseído esto trajo una molestia generalizada por parte de los padres de las víctimas muertas.

El fallo fue repudiado por familiares de víctimas y por sobrevivientes del desastre. 'Con su decisión la jueza consagra la impunidad. El jueves presentaremos una apelación', dijo el abogado querellante José Iglesias, padre de un joven que murió en el incendio. Otros parientes se mostraron más intransigentes. Poco después del mediodía alrededor de 30 familiares se movilizaron a Tribunales para protestar contra el fallo. De ahí marcharon hasta la Jefatura de Gobierno de la Ciudad, dónde, según un cable de la agencia DyN arrojaron una bomba incendiaria contra la puerta

jueces a favor de los delincuentes"”. El lugar para el disenso casi es nulo e ínfimo. " QQueremos entrar para controlar cómo votan y cómo fundamentan sus votos los legisladores', explicó Nilda Gómez, madre de Mariano Benitez (20), otra víctima del incendio. Y agregó: "Todos los padres tenemos el mismo derecho de ingresar a la sesión. Por eso, no vamos a aceptar que algunos de nosotros ingresen y otros no. O entramos todos o no entra ninguno'." (negrilla mía) "Los familiares afirman que el lunes entrarán "todos o ninguno" en Clarín, 12 de noviembre de 2005, http://www.clarin.com/diario/2005/11/12/elpais/p-00401.htm. “"Este es un movimiento del dolor, no un movimiento político', subrayó una madre, al coincidir con otros padres para que las agrupaciones políticas de izquierda ocuparan el fondo de la columna". "Diez cuadras de dolor incontenible por los 194 chicos de Cromañón" en Clarín, 31 de diciembre de 2005.

Sitio Web http://www.clarin.com/diario/2005/12/31/sociedad/s-05201.htm. 40 "La Justicia sobreseyó a Ibarra por la tragedia de Cromañón" en Clarín, 8 de agosto de 2006.

Sitio web http://www.clarin.com/diario/2006/08/08/sociedad/s-03001.htm 
principal del edificio ${ }^{41}$. (Negrilla en el original)

El lugar de la víctima posiciona a la denuncia casi como única práctica posible, siendo esta una forma de expresión que no puede ser política, ya que no pretende en ningún momento obtener poder o definir lugares de poder, sino que directamente está orientada a evitar el suceso denunciado, pero desde el dolor y la reprobación moral. Además la importancia que tiene la vulnerabilidad de los hijos antedicha incrementa que el lugar de los padres sea incuestionable políticamente o éticamente y por consiguiente hay una eximición de responsabilidad porque basta con haber sufrido.

Este desarrollo de esta liturgia de la víctima no es nuevo, pero aparece con más fuerza durante los últimos 20 años. Se podría decir que la lucha que inician las Madres de Plaza de Mayo posibilita que esta respuesta sea la única claramente posible.

Hasta hace poco tiempo, la respuesta estándar del sistema a esta crítica era que los intereses de las víctimas estaban subsumidos en el interés público y que, en definitiva, las políticas correccionalista del Estado funcionarían en interés tanto del delincuente como del público. [...] Ya desde los años ochenta, la policía, los fiscales y los jueces han comenzado a asegurarse de que las víctimas sean adecuadamente informadas, que sean tratadas con mayor sensibilidad, que se les ofrezca asistencia y que se les dé una compensación por los daños sufridos.[...] Se les ha reconocido a las víctimas una serie de derechos y se les ha dado participación en el proceso penal. ${ }^{42}$

Esta transformación termina siendo fundamental, posibilitando que este fenómeno perdure y se manifiesta de manera constante, y que, por sobre todas las cosas se establezca como la única solución posible dentro de los reclamos ante el poder judicial y ante el poder político.

La figura simbólica de la víctima ha cobrado vida 41 GARLAND, D.; La cultura del control. Crimen y orden social en la sociedad contemporánea, Barcelona, Gedisa, 2005, pp. 206-207.

42 GARLAND, D.; op. cit., p. 242. 
propia y juega un papel clave en el debate político y en la argumentación en torno a las políticas públicas. [...] la víctima del delito es ahora, en cierto sentido, un personaje representativo cuya experiencia se supone común y colectiva, en lugar de individual y atípica. El sufrimiento de la víctima (frecuentemente una mujer) se representa con el lenguaje inmediato y personalizado de los medios masivos de comunicación y se dirige directamente a los miedos y la ira de los espectadores, produciendo efectos de identificación y reforzamiento que luego son usados política y comercialmente ${ }^{43}$

Pero la consecuencia fundamental de esta homogeneidad discursiva que actúa como englobadora y representativa del discurso social tiene que ver con la despolitización. Como vimos el lugar de la familia y sus relaciones no son políticos pero tampoco lo será su discurso que tiene en su nudo fundamental los derechos humanos como centro, discurso ético fundamental que impide la concreción de un reclamo político.

Žižek explica que la despolitización del Holocausto es un acto político de absoluta manipulación ${ }^{44}$. Se puede entender que lo mismo ocurre con la prédica de los derechos humanos. Los derechos humanos se transforman en el grado cero de la discusión, lo imposible de discutir ${ }^{45}$. Si se transforma al discurso de los derechos humanos en lo pre-político entonces los derechos humanos no tienen que ver con la acción tal y como la entendía Arendt, sino por el contrario con el ámbito de la labor que había sido retraducido por el ámbito social y utilizado de una forma totalmente diferenciada y que

43

ŽIŽEK, S.; ¿Quién dijo totalitarismo? Cinco intervenciones sobre el (mal) uso de una noción, Valencia, Pre-Textos, 2002, pp. 83-84.

$44 \quad$ "Far from being pre-political, 'universal human rights' designate the precise space of politicization proper; what they amount to is the right to universality as such - the right of a political agent to assert its radical non-coincidence with itself (in its particular identity), to posit itself as the 'supernumerary', the one with no proper place in the social edifice; and thus as an agent of universality of the social itself". ŽIŽEK, S.; "AGAINST HUMAN RIGHTS”, en New Left Review 34, July-August 2005 p. 131.

45 IGNATIEFF, M. (et al.); Human Right as politics and idolatry, New Jersey, Princenton Universtity Press, 2001. pp. 56-57. 
tiende por consiguiente a poner más en riesgo la vida que reproducirla. Los derechos humanos se presentan como la protección última en que los seres humanos son respetados y defendidos en su accionar:

A human rights abuse is something more than an inconvenience, and seeking human rights redress is distinct from seeking recognition. It is about protecting an essential exercise of human agency. [...] Human rights matter because they help people to help themselves. They protect their agency. ${ }^{46}$

De esta manera queda remarcado que los derechos humanos están para proteger de manera constante y permitir el accionar humano, más aún para permitir que las personas sean ellas mismas. Por eso mismo, el discurso de los derechos humanos se presenta como lo apolítico por antonomasia, como el estado preexistente al cuerpo político y de una pureza total.

Es así que, desde el lugar de la familia esta puesta en entredicho la nuda vida y por ello cualquier contra-discurso pareciera afectar aún más a la víctima. Esto complementado con la denuncia conlleva la comprensión del hecho desde un lugar de inseguridad sin objetivos políticos concretos, transformándose en síntoma de una mirada ética.

De esta manera la cuestión encierra una terrible paradoja, la víctima se victimiza doblemente en la petición de sus derechos humanos, sin embargo sigue con su prédica. De esta manera, todo pareciera volverse vulnerable demostrando que cualquier prédica por los derechos humanos pareciera ser cerrada y dejando a varios afuera.

\section{Conclusiones}

46 "Finalmente, nesse quadro, é possivel comprender as agruras da internalização de uma idéia de Direitos Humanos e, mais ainda, de sua implementação como política pública. Os direitos, em nossa tradição, são sempre particularizados, e explica-se assim, que cada categoria reivindique competitivamente os "seus" direitos humanos: das vitimas, das policiais, dos agressores, etc., como se a "concessão" desses direitos a uns excluísse automaticamente os outros de fruí-los, como tem sido constantemente explicitado por nossos interlocutores, no campo" KANT DE LIMA, R., "Direitos civis e direitos humanos..., p. 58. 
La primera de ellas, tiene directa relación con el papel que cumplen los familiares en la calle, con su labor y con la impronta de sus movimientos. La actuación realizada por los familiares es una conducta ética que no funciona nunca como accionar político. Esto lo condiciona y lo dirige directamente a peticionar siempre para el juzgamiento de las conductas ajenas. Su referente siempre es la agencia judicial o medidas relacionadas con el castigo, con el juzgamiento.

El reclamo está destinado casi de manera excluyente al Poder Judicial, dando una preponderancia a este durante los últimos años en la Argentina, de esta manera, también pareciera que gran parte de las peticiones que antes se desarrollaban en la arena política y que implicaban solicitar a los poderes políticos alguna actuación en particular, hoy han sido trasladadas al Poder Judicial como el único que puede aportar alguna solución.

A pesar de este papel del Poder Judicial, los familiares son "expulsados" del lugar jurídico teniendo que construir su "verdad" afuera. La imposibilidad de solución de la agencia judicial, de una solución que termine por satisfacer a los familiares tiene una íntima relación con nuestra relación jurídica, como esta fue construida y como esta actúa hoy.

De ahí surgirán una serie de interrogantes que es necesario contestar para ver la eficacia política de este tipo de movimientos y también para poder saber, como ya se dijo, si este direccionamiento tiene alguna otra incidencia que no pueda ser reconocible a simple vista. En concreto se puede entrever que la existencia de los grupos familiares en la calle ha servido, en cierta forma, para el establecimiento directo de una red en dónde quedan entrampados los mismos familiares. En esta red que es de un entramado finísimo no se puede estar en contradicción con el grupo familiar, sólo se puede estar con ellos de manera directa, de manera única, y por ende, hay un rechazo manifiesto a la contradicción y a la oposición.

En segundo plano, se debe tratar de ver que la conducta de los grupos familiares, especialmente en los últimos años, pretende fortalecer el papel punitivo del Estado. Lo peticionado por los familiares, la forma de la petición condiciona entonces su logro. Condiciona, también, la respuesta estatal. Intenta establecer una imposibilidad en la oposición. Nadie puede estar en desacuerdo con lo reclamado por los grupos familiares. De manera directa su prédica es la nuestra y es imposible que sea obviada.

Esta homogeneización está acompañada por una despolitización debido al discurso que pretende sostener. El discurso que se utiliza es el de los derechos humanos que de por sí se halla despolitizado, que no puede tener 
costado político ya que no puede ser motivo de participación o discusión.

Ser familia, por ende, sigue siendo un instrumento disciplinador de manera total y social, impidiendo cualquier escape a este y a sus relaciones desiguales naturalizadas. En este punto, las últimas oleadas de grupos familiares han aportado, con claridad, en este establecimiento de la denuncia como único móvil posible, como único medio posible que todo lo puede y que todo lo consigue y que siempre es para "que no se repita" y para todos.

\section{Materiales y fuentes}

AA.VV.; Historia de las Madres de Plaza de Mayo, Buenos Aires, Editorial La Página, 1995

AGAMBEN, G.; Homo sacer. El poder soberano y la nuda vida, Valencia, Pre-textos, 1998

ARENDT, H.; ¿Qué es la política?, Barcelona, Paidos, 1997.

La condición humana, Buenos Aires, Paidos, 2003.

De la historia a la acción, Buenos Aires, Paidos, 2005.

CLARÍN. Edición electrónica del diario fecha. En http://www.clarin.com.ar

D’ALBORA, F. J.; Código Procesal Penal de la Nación. Anotado, comentado, concordado, Buenos Aires, Abeledo Perrot, 2003

FOUCAULT, M.; La verdad y las formas jurídicas, Barcelona, Gedisa, 2005

El orden del discurso, Barcelona, Tusquets, 1992

GARLAND, D.; La cultura del control. Crimen y orden social en la sociedad contemporánea, Barcelona, Gedisa, 2005

GORINI, U.; La rebelión de las madres. Historia de las Madres de Plaza de Mayo. Tomo I (1976-1983), Buenos Aires, Norma, 2006

GUAGNINI, L.; Blumberg en el nombre del hijo, Buenos Aires, 
Sudamericana, 2005

HERRERA, M. - TENENBAUM, E.; Identidad despojo y restitución, Buenos Aires, Abuelas de Plaza de Mayo, 2001

IGNATIEFF, M. (et al.); Human Right as politics and idolatry, New Jersey, Princenton Universtity Press, 2001

KANT DE LIMA, R., "Direitos civis e direitos humanos. Uma tradição

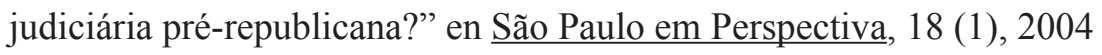

MERRYMAN, J. H.; The civil law tradition. An introduction to the legal systems of Western Europe and Latin America, Stanford, Stanford University Press, 1969

REPÚBLICA ARGENTINA, Código Procesal Penal de la Nación Argentina

ŽIŽEK, S.; ¿Quién dijo totalitarismo? Cinco intervenciones sobre el (mal) uso de una noción, Valencia, Pre-Textos, 2002

"AGAINST HUMAN RIGHTS", en New Left Review 34, July-August, 2005. 